\title{
The role of human milk and sucrose on cariogenicity of microcosm biofilms
}

\section{Cácia SIGNORI(a) Andréia Drawanz HARTWIG(a) Ivam Freire da SILVA-JÚNIOR(a) Marcos Britto CORREA(a) Marina Sousa AZEVEDO(a) Maximiliano Sérgio CENCI(a)}

(a) Universidade Federal de Pelotas - UFPel, School of Dentistry, Graduate Program in Dentistry, Pelotas, RS, Brazil.

Declaration of Interests: The authors certify that they have no commercial or associative interest that represents a conflict of interest in connection with the manuscript.

\section{Corresponding Author:}

Marina Sousa Azevedo

E-mail: marinasazevedo@hotmail.com

hitps://doi.org/10.1590/1807-3107bor-2018.vol32.0109

Submitted: March 13, 2018

Accepted for publication: August 03, 2018

Last revision: September 05, 2018

\begin{abstract}
This study investigated the effect of human milk, alone and associated with sucrose, in the cariogenicity of biofilms in a microcosm biofilm model and compared with the cariogenicity of sucrose and bovine milk. Microcosm biofilms were grown in enamel discs in 24-well plates. Six growth conditions were studied: DMM (chemically defined artificial saliva - negative control), DMM with 1\% of sucrose (DMM+s) (positive control), human milk with DMM, human milk with DMM+s, bovine milk with DMM, and bovine milk with DMM+s. After 5 days, the outcome variables surface hardness change (\%SHC), microbiological composition of biofilms, and $\mathrm{pH}$ of supernatant were analyzed. All groups had significantly lower hardness loss compared to the DMM group with $1 \%$ of sucrose. Human and bovine milk associated with sucrose showed higher hardness loss. The supernatant $\mathrm{pH}$ values after 6 hours of different treatments were similar for the groups sucrose and human milk associated with sucrose $(p>0.05)$. After 18 hours at rest in pure $\mathrm{DMM}$, an increase in the $\mathrm{pH}$ of the supernatant was observed. Higher values of total microorganisms count were found for sucrose and bovine milk groups compared to the group supplemented only by DMM. Bovine milk group showed greater amount of total aciduric microorganisms in comparison to human milk group. Within the limits of this study, it can be infered that both human and cow milks have some cariogenic potential, although differing from sucrose in terms of mineral loss.
\end{abstract}

Keywords: Dental Caries; Milk; Humans; Sucrose; Biofilms.

\section{Introduction}

The benefits of breastfeeding extend far beyond the ideal nutritional source for infants. Studies have shown that human milk can reduce child mortality, infectious diseases, ${ }^{1}$ obesity, and diabetes. ${ }^{2}$ Besides, breastfeeding has long-term benefits on the individual and society. ${ }^{3}$

The relationship between human milk and dental caries development has been discussed in the literature with controversial results. ${ }^{4,5,6,7,8}$ Most observational studies have shown that children exposed to prolonged breastfeeding appear to develop more dental caries.,10,11 However, these findings should be interpreted with caution as they may be linked to other confounding factors not adequately controlled, such as cariogenic foods and drinks in the diet and inadequate oral hygiene practices. ${ }^{12}$ 
Aiming to answer specific questions related to human milk and caries development under controlled conditions, in vitro, in situ, and animal models have been used to test the cariogenicity of milk. ${ }^{13,14,15,16}$ Most of these studies showed that human milk has some potential to promote caries development, especially when supplemented with sugar. ${ }^{14}$ However, biofilms were grown in the absence of saliva, ${ }^{13,14}$ with longer periods of plain milk immersion, ${ }^{16}$ and in a monoculture biofilm. ${ }^{17}$

Different biofilm models have been used to understand how diet and other compounds affect cariogenicity. These models can be dynamic, with complex systems that allow manipulation of the salivary flow and $\mathrm{pH}$ fluctuations, ${ }^{18}$ or of simpler structure, with development of the biofilms in microplates, indicated for the investigation of several conditions at the same time. ${ }^{19}$ The biofilm models are normally originated from a natural ecosystem (microcosm) that maintains the heterogeneity and the complexity of oral microbiota under controlled conditions..$^{20}$ In microcosm models, the diversity of oral flora (greater than 700 species) ${ }^{21}$ are maintained by the oral inoculum provided, most typically saliva from a donor. However, this model has not been used yet to address the cariogenic potential of human milk. It can be hypothesized that in more realistic conditions this potential could be weakened or nullified. Thus, the use of a controlled biofilm model may elucidate controversial questions regarding the cariogenicity of breast milk, contributing to the production of scientific evidence in this regard.

Therefore, this research aimed to determine the effect of human milk, alone and associated with sucrose, on the cariogenicity of biofilms in a microcosm biofilm model and compare with the cariogenicity of sucrose and bovine milk.

\section{Methodology}

\section{Ethical aspects}

The study was approved by the Human Research Ethics Committee of the Federal University of Pelotas (UFPel), School of Dentistry, Pelotas, Brazil (protocol number 1.550.920) and written informed consent was obtained from the donors of saliva and human milk.

\section{Experimental design}

The microcosm biofilm model previously described by van de Sande et al. was used in this in vitro study. ${ }^{19}$ Human stimulated saliva was used as the inoculum to provide a multispecies biofilm. The biofilms were submitted to the treatments for 6 hours and to a chemically defined saliva analogue enriched with mucin (DMM) 22 for 18 hours.

Discs of bovine enamel were used as biofilm growth substrate. The specimens were divided according to the growth treatment into 6 groups: DMM (no treatment - negative control), DMM with $1 \%$ of sucrose $(\mathrm{DMM}+\mathrm{s})$ (positive control), human milk with DMM, human milk with DMM+s, bovine milk with DMM and bovine milk with DMM+s. The experiment was run in quintuplicate. The growth medium was renewed twice a day and the biofilms were grown under alternate exposure to DMM for 18 hours and the treatment for $6 \mathrm{~h}$, during 5 days. The outcome variables analyzed were mineral loss, recorded as the percentage of surface microhardness change (\%SHC), microbiological composition of biofilms, and supernatant $\mathrm{pH}$.

\section{Preparation of bovine enamel discs}

Enamel discs from recently extracted bovine central incisors were obtained with a cylindrical diamond-coated drill. Enamel and dentine surfaces were ground with sanding paper (particle size $320 / 600 / 1200 / 1500$ ) to get parallel surfaces, and then enamel surfaces were polished with felt discs and diamond paste. The specimens were protected with nail varnish, leaving only the enamel surface free of varnish. Surface microhardness $(\mathrm{SMH})$ was assessed by making 3 indentations in the center of the discs at a distance of $50 \mu \mathrm{m}$ from each other, with a Knoop diamond point ( $50 \mathrm{~g}$ load for $5 \mathrm{~s}$ ) in a microhardness tester (HMV-2000; Shimadzu Corporation, Tokyo, Japan). The average values of the 3 indentations were obtained for each specimen. The mean value of baseline hardness of the selected discs was 245.92. The discs were sterilized by gamma radiation.

\section{Preparation of the milk solutions}

Human milk was collected from a single healthy donor (32 years old, non-smoker, caries-free, with 
healthy periodontal condition, and without any systematic disease and/or use of medication). The donor was a lactating mother of a 4-month-old baby and the milk was collected twice, in the day prior to the beginning of the experiment and in the third day of the experiment ( 3 falcon tubes of $50 \mathrm{~mL}$ each time) after the baby had fed from the opposite breast. For the collection, the donor used a hair cap and a mouth and nose mask. Before each collection, the donor washed her hands with water and liquid soap and after discarding the first milk ( 0.5 to $1 \mathrm{~mL})$, the milk was collected using a manual extractor device in sterile falcon tube and sealed immediately after collection. The tubes were stored at $-20^{\circ} \mathrm{C}$ immediately after collection until use.

The bovine milk processed in UHT (ultrahigh temperature) was obtained from a Brazilian commercial trademark (whole milk Tirol, Santa Catarina, Brazil). The nutritional content of bovine milk was $9 \mathrm{~g}$ carbohydrate, $6 \mathrm{~g}$ proteins, $6 \mathrm{~g}$ total fat, $3 \mathrm{~g}$ saturated fats, $130 \mathrm{mg}$ calcium, and $210 \mathrm{mg}$ sodium per $100 \mathrm{~mL}$.

The milk solutions were prepared prior to each medium exchange. In each day of experiment, 20 minutes before use, a falcon tube was retrieved from the freezer and placed in a container containing water at room temperature. The milks were diluted in DMM or DMM+s according to the treatment group. For this, 4 sterile falcon tubes were filled with $6 \mathrm{~mL}$ of milk each (2 tubes with breast milk and 2 tubes with bovine milk). Then $6 \mathrm{~mL}$ of DMM were added in one of the tubes containing breast milk or bovine milk, and DMM with 1\% sucrose in the remaining two tubes. The solutions were agitated and vortexed prior to use.

\section{Biofilm growth}

The enamel discs were suspended in 24 multiwell microplates, one per each well. The specimens were initially inoculated with saliva $(400 \mu \mathrm{L}$ each) collected from a healthy donor (male, 19 years old, non-smoker, caries-free and with healthy periodontal condition), $24 \mathrm{~h}$ after the last oral hygiene, and $2 \mathrm{~h}$ after the last meal. There was no restriction regarding the diet for the donor $24 \mathrm{~h}$ before saliva collection. The microplates containing the specimens inoculated with saliva were maintained at incubation for 1 hour. After that, $1.8 \mathrm{~mL}$ of the DMM, DMM+s, and milk solutions were added to each well, according to the groups. The saliva previously inoculated was not withdrawn from the wells. Biofilms were exposed to the treatment for $6 \mathrm{~h}$ and to pure DMM for $18 \mathrm{~h}$ each day. The media were renewed daily, and at each exchange, the specimens were carefully washed in sterile saline and deposited in 24-well plates containing the new medium. The biofilms were incubated under anaerobic atmosphere $\left(5-10 \% \mathrm{CO}_{2},<1 \% \mathrm{O}_{2}\right)$ at $37^{\circ} \mathrm{C}$, during the 5 days of growth.

\section{pH measurements}

The $\mathrm{pH}$ of the supernatant DMM and of the treatments was recorded daily in each well from the discarded plate after the medium was replaced (Quimis 50w - Quimis Aparelhos Científicos Ltda, Diadema, SP, Brazil; V621 electrode - Analion, Ribeirão Preto, SP, Brazil).

\section{Biofilm microbial composition analysis}

After 5 days of growth, the biofilm formed on enamel surfaces was collected with a sterile plastic instrument and placed in microtubes. The biofilms were sonicated and serially diluted in sterile saline $\left(10^{0}-10^{-7}\right)$ and inoculated in duplicate onto blood agar (for total microorganisms' counts), brain heart infusion adjusted to $\mathrm{pH} 4.8$ (for total aciduric bacteria counts), and rogosa agar (for total lactobacilli). The plates were incubated in anaerobic jars $\left(5-10 \% \mathrm{CO}_{2},<1 \% \mathrm{O}_{2}\right)$ for $96 \mathrm{~h}$ at $37^{\circ} \mathrm{C}$, and the colony forming units (CFUs) were counted by one blinded and trained operator. The counts were expressed as CFUs / milligram of biofilm (dry weight).

\section{Microhardness change analysis}

After the growth period, microhardness measurements of enamel discs were obtained again with a hardness tester (Micro Hardness Tester FM 700, Future-Tech Corp., Kawasaki, Japan) using the previous parameters to evaluate the initial hardness of the specimens. The percentage of surface microhardness change (\%SHC) was calculated by the following formula: \%SHC $=100(\mathrm{SMH} 2-\mathrm{SMH}) / \mathrm{SMH}$, where $\mathrm{SMH}$ is the average of the initial (baseline) 
microhardness measurements, and SMH2 is the average of the final (after growth) microhardness values. The SMH determination of all enamel discs was carried out by one blind and trained examiner.

\section{Statistical analysis}

The sample size was calculated based on an adequate power of $90 \%$ and a significance level of $5 \%$ $(\mathrm{p}<0.05)$ considering a \%SHC between DMM (6.5) and DMM supplement by sucrose (85.0) and mean standard deviation (6.8). ${ }^{23}$ The number of specimens was 5 for each group, totalizing a sample of 30 (5 specimens $x 6$ growth conditions).

The mean of 5 specimens in each group was calculated for each outcome (surface microhardness change, microbiological composition of biofilms, and supernatant $\mathrm{pH}$ ). To compare the results between groups $(p<0.05)$, the data of each specimen was used and the groups identified in the statistical program. Statistical comparisons for the outcome variables surface hardness changes, CFU counts, and supernatant $\mathrm{pH}$ after rest (18 $\mathrm{h}$ in DMM) were determined by one-way ANOVA followed by pairwise comparisons with Tukey's method. Equality of variances and the normal distribution of errors were checked for each variable. Total lactobacilli and total aciduric bacteria data were log10 transformed. Total microorganisms were rank transformed, and mutans streptococci converted to exponential numbers. Data from $\mathrm{pH}$ measurements after treatment (6 hours) were analyzed by one-way ANOVA for ranks. The significance level was set at $5 \%$ and SigmaStat version 4.0 was used (Systat Software Inc., London, UK).

\section{Results}

All groups had significantly lower hardness loss [DMM (2.8\%), human milk with DMM (24.7\%), human milk with DMM+s (46.9\%), bovine milk with DMM (4.7\%) and bovine milk with DMM+s (88.2)] compared to the DMM group with $1 \%$ sucrose $(\mathrm{p}<0.005)$, which showed $88.2 \%$ of hardness loss (Figure 1). Comparing only groups containing milk, human milk with $\mathrm{DMM}+\mathrm{s}$ and bovine milk with DMM+s showed higher hardness loss, however were significantly similar to human milk without sucrose and bovine milk without sucrose $(p=0.178, p=0.09)$. The negative control (DMM) presented the lowest hardness loss and was similar to all treatment groups [human milk ( $p=0.636)$; bovine $(\mathrm{p}=1.000)$; bovine milk $+\mathrm{s}$ $(p=0.059)]$ except in comparison to human milk with $\mathrm{DMM}+\mathrm{s}(\mathrm{p}=0.006)$.

A pattern of $\mathrm{pH}$ fluctuations was observed for each group comparing the $\mathrm{pH}$ measured after 6 and 18 hours, during the 5 days of growth, except for the DMM group (Table). The supernatant $\mathrm{pH}$ values after 6 hours of different treatments were statistically similar comparing human milk associated with sucrose and sucrose groups $(p>0.05)$. The bovine milk group showed the highest $\mathrm{pH}$ values compared to the other treatment groups, except to the control group

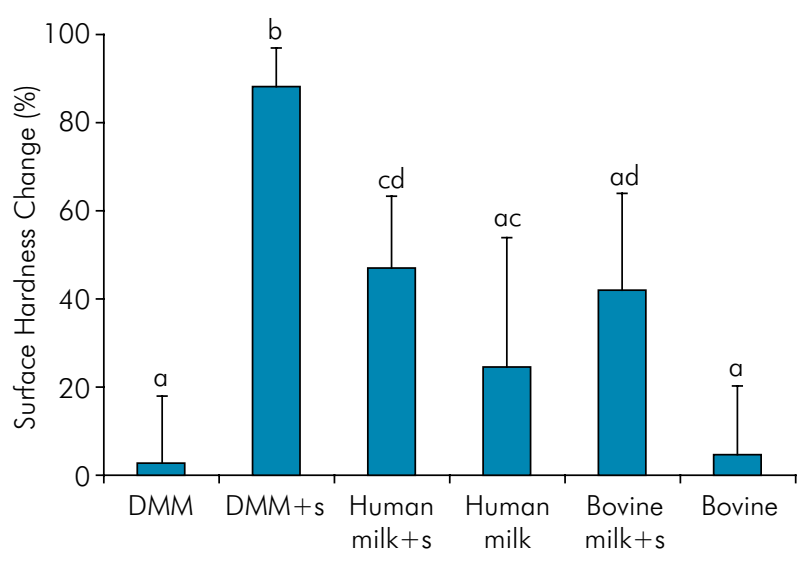

Figure 1. Surface hardness change (\%) and standard deviation (SD) according to the growth condition of biofilms. Distinct letters indicate significant difference among groups $(p<0.05)$.

Table. Mean values of supernatant $\mathrm{pH}$ according to the growth condition.

\begin{tabular}{llccc}
\hline \multirow{2}{*}{ Growth condition } & \multicolumn{2}{c}{ After 6 hours } & \multicolumn{2}{c}{ After 18 hours } \\
\cline { 2 - 5 } & \multicolumn{2}{c}{ (treatment) } & \multicolumn{2}{c}{ (DMM) } \\
\cline { 2 - 5 } & Mean & SD & Mean & SD \\
\hline DMM & $6.42^{\mathrm{a}}$ & 1.51 & $6.82^{\mathrm{a}}$ & 1.61 \\
Sucrose & $3.82^{\mathrm{b}}$ & 0.90 & $6.60^{\mathrm{b}}$ & 1.55 \\
Human milk+s & $3.93^{\mathrm{be}}$ & 0.91 & $6.42^{\mathrm{cd}}$ & 1.49 \\
Human milk + DMM & $4.11^{\mathrm{de}}$ & 0.95 & $6.53^{\mathrm{bd}}$ & 1.51 \\
Bovine milk+s & $4.25^{\mathrm{cd}}$ & 0.99 & $6.26^{\mathrm{c}}$ & 1.47 \\
Bovine + DMM & $4.53^{\mathrm{ac}}$ & 1.05 & $6.16^{\mathrm{c}}$ & 1.46 \\
\hline
\end{tabular}

Different letters indicate significant difference within each time (after 6 hours and after 18 hours) $(p<0.05)$. 
(DMM). There was no statistical difference between the bovine milk group and the group submitted to pure DMM ( $\mathrm{p}>0.05)$.

After 18 hours at rest in pure DMM, an increase in the supernatant $\mathrm{pH}$ was observed for all groups. The negative control group (DMM) remained with a stable $\mathrm{pH}$ compared to the $\mathrm{pH}$ after 6 hours. The negative control group was statistically different from the treatment groups $(p<0.001)$ and positive control group $(\mathrm{p}=0.039)$ considering the $\mathrm{pH}$ after 18 hours. Still, after 18 hours, the groups submitted to maternal and bovine milk showed differences ( $p=0.008)$, however when each milk was associated with sucrose, $\mathrm{pH}$ values were similar between these 2 groups $(p=0.747)$.

Higher total microorganisms counts were found for sucrose and bovine milk groups (Figure 2a), significantly difference compared to the group supplemented only with DMM ( $p=0.01 ; p=0.007$, respectively). No growth was observed for lactobacilli and total aciduric bacteria in the DMM group, resulting in a significant difference compared to the other groups ( $\mathrm{p}<0.001$ ) (Figures $2 \mathrm{~b}$ and $2 \mathrm{c}$ ). Bovine milk group showed greater amount of total aciduric microorganisms in comparison to human milk group $(p=0.019)$.

\section{Discussion}

This is the first study to address the cariogenicity of human milk using a microcosm biofilm model. The results showed that although human milk has cariogenic potential, this potential is less expressive than that of sucrose. The addition of sucrose to human milk increased demineralization but was statistically similar to milk without addition of sucrose, not reaching the levels of demineralization of sucrose alone, which caused the highest mineral loss.

Recent clinical and epidemiological studies have brought attention to the cariogenic potential of human milk. ${ }^{911}$ However, this cariogenic potential usually is associated to prolonged breastfeeding, and to children being also exposed to other cariogenic fluids and solids. ${ }^{10,24}$ A recent systematic review showed a higher risk for dental caries in children breastfed for more than 12 months. However, the authors highlight that the studies supporting this association have failed in controlling the analyses for important confounders of this relationship, such as
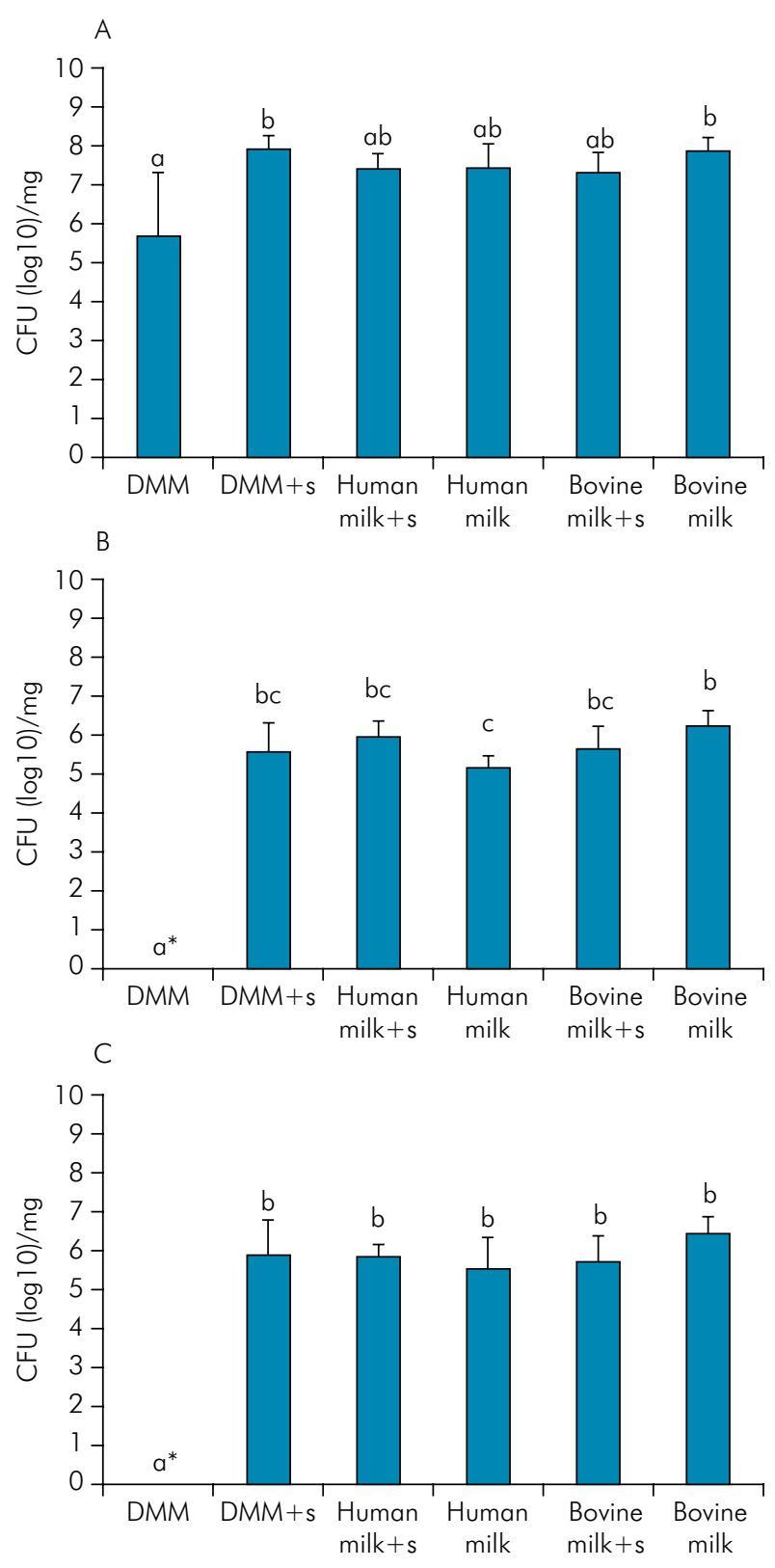

Figure 2. a. CFU values of total microorganisms grown onto blood agar, according to the growth condition after 5 days. Distinct letters indicate significant difference among groups ( $p<0.05$ ). b. CFU values of total aciduric bacteria grown onto brain heart infusion adjusted to $\mathrm{pH} 4.8$ according to the growth condition after 5 days. Distinct letters indicate significant difference among groups ( $p<0.05$ ). c. CFU values of lactobacilli grown onto rogosa agar according to the growth condition after 5 days. Distinct letters indicate significant difference among groups ( $p<0.05)$. 
the intake of sweetened drinks and food, oral hygiene habits, and oral health status of mothers. Therefore, the idea of a combined effect between cariogenic food and breastfeeding is still under investigation. ${ }^{25}$ Moreover, the cariogenicity of human milk seems to be more associated to prolonged breastfeeding and several nighttime breastfeeding sessions. ${ }^{26,27}$ In this sense, breastfeeding is pointed out as a protective factor against early-childhood caries, ${ }^{28}$ while cohort and trajectory studies show no association between breastfeeding duration and dental caries. ${ }^{29,30}$

Regarding the cariogenicity of human milk, in vitro and in vivo studies have shown controversial results. Prabhakar et al. found that human and bovine milk are relatively cariogenic increasing the cariogenicity with the addition of an external source of carbohydrate. ${ }^{14}$ Another study carried out with rats showed that human milk has some potential to promote caries development, being more cariogenic than cow milk. The explanation for this finding is that human milk presents lower mineral content and more lactose than cow milk. ${ }^{13}$ However, these studies used models in the absence of saliva, which could overestimate the cariogenic potential of solutions.

On the other hand, Neves et al. assessed dental biofilm cariogenicity of children after exposure to sucrose and human milk (breastfeeding) and verified that human milk did not decreased $\mathrm{pH}$, while sucrose provoked a significant $\mathrm{pH}$ decrease. According to the authors, human milk is not cariogenic because it is incapable of causing a $\mathrm{pH}$ drop that could demineralize enamel..$^{31}$ Differently, our findings showed that human milk caused a $\mathrm{pH}$ drop capable of inducing enamel demineralization. In addition, this drop was higher compared with bovine milk, which performed similar to control group regarding acidogenicity potential. It can be hypothesized that the amount of lactose present in human milk was enough to cause the $\mathrm{pH}$ to drop below the critical level for enamel demineralization, and this effect was probably increased by the small volume of culture media or treatments used in the 24-weel model for biofilm growth. If a continuous flow model had been used, the $\mathrm{pH}$ drop caused by both human and bovine milk could be lower than the threshold for enamel demineralization. However, we must also consider that there was significant difference between the supernatant $\mathrm{pH}$ of DMM with $1 \%$ sucrose and human milk with DMM, and that there was no statistical difference for demineralization between the human milk with DMM group and the DMM group (no treatment - negative control), which could suggest that if human milk were the only source of carbohydrate in the child's diet, it would not be acidogenic. Future studies should address this question. Corroborating previous findings, sucrose presented the highest acidogenic potential. ${ }^{15,31,32}$

The addition of sucrose to both milks did not affect the $\mathrm{pH}$ measurements in the supernatant compared with plain milks as could be expected. Likewise, microbiota composition did not differ among tested solutions based on the lactobacilli counting, except for pure DMM group. In addition, although the bovine milk group showed greater amount of total aciduric microorganisms in comparison to human milk group, all tested solutions presented expressive amounts of aciduric microorganisms. The explanation for this fact can be the static biofilm model used in this study. Since this study used a semi-continuous model, the $\mathrm{pH}$ drops were probably overestimated. Unfortunately, we could not measure biofilm $\mathrm{pH}$ in real time, which is a limitation of the study. Based on the ecological understanding of caries development, ${ }^{33}$ in persistently low $\mathrm{pH}$, aciduric and acidogenic bacteria would be selected. In a closed system, the presence of a small proportion of glucose could enhance the cariogenicity of lactose, of which human milk has a high content. ${ }^{34}$ Although this semi-continuous model presents some strengths, allowing biofilm formation under controlled conditions and the replication of the variability and heterogeneity of plaques in vivo, a dynamic model could simulate more precisely the complexity of the oral environment ${ }^{23,35}$ including salivary flow and $\mathrm{pH}$ oscillations from exposure to cariogenic conditions ${ }^{36}$ as well as the shear stresses that might influence bacterial attachment. ${ }^{18}$ This hypothesis should be tested in future studies.

Human milk presented some cariogenic potential, because it showed lower $\mathrm{pH}$ than the negative control (DMM) and, although there was no statistical difference, higher mineral loss and microorganism counts than the DMM group. The addition of sucrose to milks increased their cariogenic potential, since a 
higher hardness loss was found, although similar to the respective milk without addition of sucrose. Both human and cow milks present protective action against caries including the anticariogenic properties of casein, whey proteins, and milk fat that could explain our findings. ${ }^{37}$ On the other hand, one cannot discard the hypothesis that the decreased effect of sucrose when combined with milks was due to its lower concentration on prepared milks solutions. Because milk naturally has other fermentable carbohydrates such as glucose and lactose, the addition of the same proportion of sucrose used in the positive control would overestimate the cariogenic effect of milks.

In addition, although not statistically different, there was a trend for the bovine milk with sucrose to present a greater mineral loss than the negative control. Probably, a larger sample would yield a significant difference between the two groups. Also, some limitations should be taken into account when interpreting the results of this study. As a single donor of human milk was used, it is important to take into consideration that breast milk varies between individuals, such as in lactose level, ${ }^{38}$ thus, future studies could explore this variation and its impact in milk cariogenicity. Another limitation is the use of the semi-dynamic biofilm model. Although considered a good alternative compared to other biofilm models,

\section{References}

1. Horta BL, Victora CG. Long-term effects of breastfeeding: a systematic review. Geneve: World Health Organization; 2013.

2. Ip S, Chung M, Raman G, Chew P, Magula N, DeVine D et al. Breastfeeding and maternal and infant health outcomes in developed countries. Evid Rep Technol Assess (Full Rep). 2007 Apr;(153):1-186.

3. Victora CG, Horta BL, Loret de Mola C, Quevedo L, Pinheiro RT, Gigante DP et al. Association between breastfeeding and intelligence, educational attainment, and income at 30 years of age: a prospective birth cohort study from Brazil. Lancet Glob Health. 2015 Apr;3(4):e199-205. https://doi.org/10.1016/S2214-109X(15)70002-1

4. Campus G, Solinas G, Strohmenger L, Cagetti MG, Senna A, Minelli $L$ et al. National pathfinder survey on children's oral health in Italy: pattern and severity of caries disease in 4-year-olds. Caries Res. 2009;43(2):155-62. https://doi.org/10.1159/000211719 the model used does not allow for simulation of $\mathrm{pH}$ oscillations from dietary carbohydrate exposure and salivary flow that influence the development of the biofilm, which is possible only in the dynamic models of continuous flow. ${ }^{39}$

Based on the present results, it can be infered that both human and cow milks have some cariogenic potential, although differing from sucrose in terms of mineral loss. Future studies should incorporate dynamic microcosm biofilm model to confirm these findings. In addition, despite the cariogenic potential of human milk, breastfeeding practices must be encouraged for the several proven benefits in children and positive impacts on health outcomes during the life course.,40,41,42 The population context is a factor that must be taken into account before affirming that breastfeeding is a risk factor for the development of dental caries. ${ }^{43}$

\section{Acknowledgements}

The authors thank the laboratory technician Lizângela Ferreira (Microbiological Laboratory School of Dentistry, UFPel, Pelotas, RS, Brazil). This study was supported by grants from $\mathrm{CNPq}$ - National Council for Research and Development/Brazil (CNPq proc\#486810/2012-7). The funding institution had no role in study design, data collection and analysis, decision to publish, or preparation of the manuscript.

\footnotetext{
5. Dye BA, Shenkin JD, Ogden CL, Marshall TA, Levy SM, Kanellis MJ. The relationship between healthful eating practices and dental caries in children aged 2-5 years in the United States, 1988 1994. J Am Dent Assoc. 2004 Jan;135(1):55-66. https://doi.org/10.14219/jada.archive.2004.0021

6. lida $H$, Auinger $P$, Billings RJ, Weitzman $M$. Association between infant breastfeeding and early childhood caries in the United States. Pediatrics. 2007 Oct;120(4):e944-52. https://doi.org/10.1542/peds.2006-0124

7. Kramer MS, Vanilovich I, Matush L, Bogdanovich N, Zhang $X$, Shishko $G$ et al. The effect of prolonged and exclusive breast-feeding on dental caries in early school-age children. New evidence from a large randomized trial. Caries Res. 2007;41(6):484-8. https://doi.org/10.1159/000108596
} 
8. Sayegh A, Dini EL, Holt RD, Bedi R. Oral health, sociodemographic factors, dietary and oral hygiene practices in Jordanian children. J Dent. 2005 May;33(5):379-88. https://doi.org/10.1016/i.jdent.2004.10.015

9. Chaffee BW, Feldens CA, Vítolo MR. Association of long-duration breastfeeding and dental caries estimated with marginal structural models. Ann Epidemiol. 2014 Jun;24(6):448-54. https://doi.org/10.1016/i.annepidem.2014.01.013

10. Feldens CA, Giugliani ER, Vigo A, Vítolo MR. Early feeding practices and severe early childhood caries in four-year-old children from southern Brazil: a birth cohort study. Caries Res. 2010;44(5):445-52. https://doi.org/10.1159/000319898

11. Peres KG, Nascimento GG, Peres MA, Mittinty MN, Demarco FF, Santos IS et al. Impact of Prolonged Breastfeeding on Dental Caries: A Population-Based Birth Cohort Study. Pediatrics. 2017 Jul;140(1):e20162943. https://doi.org/10.1542/peds.2016-2943

12. Richards D. Breastfeeding up to 12 months of age not associated with increased risk of caries. Evid Based Dent. 2016 Sep;17(3):75-6. https://doi.org/10.1038/si.ebd.6401183

13. Bowen WH, Lawrence RA. Comparison of the cariogenicity of cola, honey, cow milk, human milk, and sucrose. Pediatrics. 2005 Oct;116(4):921-6. https://doi.org/10.1542/peds.2004-2462

14. Prabhakar AR, Kurthukoti AJ, Gupta P. Cariogenicity and acidogenicity of human milk, plain and sweetened bovine milk: an in vitro study. J Clin Pediatr Dent. 2010;34(3):239-47. https://doi.org/10.17796/icpd.34.3.1k08I57045043444

15. Rugg-Gunn AJ, Roberts GJ, Wright WG. Effect of human milk on plaque $\mathrm{pH}$ in situ and enamel dissolution in vitro compared with bovine milk, lactose, and sucrose. Caries Res. 1985;19(4):327-34. https://doi.org/10.1159/000260863

16. Thomson ME, Thomson CW, Chandler NP. In vitro and intra-oral investigations into the cariogenic potential of human milk. Caries Res. 1996;30(6):434-8. https://doi.org/10.1159/000262356

17. Wernersson J, Danielsson Niemi L, Einarson S, Hernell O, Johansson I. Effects of human milk on adhesion of Streptococcus mutans to saliva-coated hydroxyapatite in vitro. Caries Res. 2006;40(5):412-7. https://doi.org/10.1159/000094287

18. Tang G, Yip HK, Cutress TW, Samaranayake LP. Artificial mouth model systems and their contribution to caries research: a review. J Dent. 2003 Mar;31(3):161-71. https://doi.org/10.1016/S0300-5712(03)00009-5

19. van de Sande FH, Azevedo MS, Lund RG, Huysmans $M C$, Cenci MS. An in vitro biofilm model for enamel demineralization and antimicrobial dose-response studies. Biofouling. 2011 Oct;27(9):1057-63. https://doi.org/10.1080/08927014.2011.625473

20. Rudney JD, Chen R, Lenton P, Li J, Li Y, Jones RS et al. A reproducible oral microcosm biofilm model for testing dental materials. J Appl Microbiol. 2012 Dec;113(6):1540-53. https://doi.org/10.1111/i.1365-2672.2012.05439.x
21. Dewhirst FE, Chen T, Izard J, Paster BJ, Tanner AC, Yu WH et al. The human oral microbiome. J Bacteriol. 2010 Oct;192(19):5002-17. https://doi.org/10.1128/JB.00542-10

22. Wong L, Sissons C. A comparison of human dental plaque microcosm biofilms grown in an undefined medium and a chemically defined artificial saliva. Arch Oral Biol. 2001 Jun;46(6):477-86. https://doi.org/10.1016/S0003-9969(01)00016-4

23. Azevedo MS, Sande FH, Romano AR, Cenci MS. Microcosm biofilms originating from children with different caries experience have similar cariogenicity under successive sucrose challenges. Caries Res. 2011;45(6):510-7. https://doi.org/10.1159/000331210

24. Hong CH, Bagramian RA, Hashim Nainar SM, Straffon LH, Shen L, Hsu CY. High caries prevalence and risk factors among young preschool children in an urban community with water fluoridation. Int J Paediatr Dent. 2014 Jan;24(1):32-42. https://doi.org/10.1111/ipd.12023

25. Tham R, Bowatte G, Dharmage SC, Tan DJ, Lau MX, Dai $X$ et al. Breastfeeding and the risk of dental caries: a systematic review and meta-analysis. Acta Paediatr. 2015 Dec;104(467):62-84. https://doi.org/10.1111/apa.13118

26. Brignardello-Petersen R. Breast-feeding up to 11 months associated with lower decayed, missing, and filled surfaces index and lower caries prevalence up to 4 years of age. J Am Dent Assoc. 2017 May;148(5):e44. https://doi.org/10.1016/i.adaj.2017.02.014

27. Un Lam C, Khin LW, Kalhan AC, Yee R, Lee YS, Chong MF et al. Identification of Caries Risk Determinants in Toddlers: Results of the GUSTO Birth Cohort Study. Caries Res. 2017;51(4):271-82. https://doi.org/10.1159/000471811

28. Birungi N, Fadnes LT, Kasangaki A, Nankabirwa V, Okullo I, Lie SA et al. Assessing causal effects of early life-course factors on early childhood caries in 5-year-old Ugandan children using directed acyclic graphs (DAGs): A prospective cohort study. Community Dent Oral Epidemiol. 2017 Dec;45(6):512-21. https://doi.org/10.1111/cdoe.12314

29. Bernabé $E$, MacRitchie $H$, Longbottom C, Pitts NB, Sabbah W. Birth weight, breastfeeding, maternal smoking and caries trajectories. J Dent Res. 2017 Feb;96(2):171-8. https://doi.org/10.1177/0022034516678181

30. Nirunsittirat A, Pitiphat W, McKinney CM, DeRouen TA, Chansamak N, Angwaravong $O$ et al. Breastfeeding Duration and Childhood Caries: A Cohort Study. Caries Res. 2016;50(5):498-507. https://doi.org/10.1159/000448145

31. Neves PA, Ribeiro CC, Tenuta LM, Leitão TJ, Monteiro-Neto V, Nunes AM et al. Breastfeeding, Dental Biofilm Acidogenicity, and Early Childhood Caries. Caries Res. 2016;50(3):319-24. https://doi.org/10.1159/000445910

32. Hassan $H$, Lingström $P$, Carlén $A$. Plaque $\mathrm{pH}$ in cariesfree and caries-active young individuals before and after frequent rinses with sucrose and urea solution. Caries Res. 2015;49(1):18-25. https://doi.org/10.1159/000360798 
33. Marsh PD. Dental plaque as a biofilm and a microbial community - implications for health and disease. BMC Oral Health. 2006 Jun;6 Suppl 1:S14. https://doi.org/10.1186/1472-6831-6-S1-S14

34. Grote V, Verduci E, Scaglioni S, Vecchi F, Contarini G, Giovannini $M$ et al. Breast milk composition and infant nutrient intakes during the first 12 months of life. Eur J Clin Nutr. 2016 Feb;70(2):250-6. https://doi.org/10.1038/ejcn.2015.162

35. Signori C, Sande FH, Maske TT, Oliveira EF, Cenci MS. Influence of the Inoculum Source on the Cariogenicity of in vitro Microcosm Biofilms. Caries Res. 2016;50(2):97-103. https://doi.org/10.1159/000443537

36. Maske TT, Brauner KV, Nakanishi L, Arthur RA, Sande $\mathrm{FH}$, Cenci MS. An in vitro dynamic microcosm biofilm model for caries lesion development and antimicrobial dose-response studies. Biofouling. 2016;32(3):339-48. https://doi.org/10.1080/08927014.2015.1130824

37. Shetty V, Hegde AM, Nandan S, Shetty S. Caries protective agents in human milk and bovine milk: an in vitro study. J Clin Pediatr Dent. 2011;35(4):389-92. https://doi.org/10.17796/icpd.35.4.r1668v3l38mh8404

38. Mitoulas LR, Kent JC, Cox DB, Owens RA, Sherriff $J L$, Hartmann PE. Variation in fat, lactose and protein in human milk over $24 \mathrm{~h}$ and throughout the first year of lactation. Br J Nutr. 2002 Jul;88(1):29-37. https://doi.org/10.1079/BJN2002579

39. Maske TT, Sande FH, Arthur RA, Huysmans MC, Cenci MS. In vitro biofilm models to study dental caries: a systematic review. Biofouling. 2017 Sep;33(8):661-75. https://doi.org/10 .1080/08927014.2017.1354248 PMID:28792234

40. Horta BL, Victora CG. Breastfeeding and adult intelligence: authors' reply. Lancet Glob Health. 2015 Sep;3(9):e522. https://doi.org/10.1016/S2214-109X(15)00066-2

41. Mola CL, Horta BL, Gonçalves H, Quevedo LA, Pinheiro $R$, Gigante DP et al. Breastfeeding and mental health in adulthood: A birth cohort study in Brazil. J Affect Disord. 2016 Sep;202:115-9. https://doi.org/10.1016/i.jad.2016.05.055

42. Victora CG, Bahl R, Barros AJ, França GV, Horton $S$, Krasevec J et al. Breastfeeding in the 21 st century: epidemiology, mechanisms, and lifelong effect. Lancet. 2016 Jan;387(10017):475-90. https://doi.org/10.1016/S0140-6736(15)01024-7

43. Peres KG, Chaffee BW, Feldens CA, Flores-Mir C, Moynihan $P$, Rugg-Gunn A. Breastfeeding and oral health: evidence and methodological challenges. J Dent Res. 2018 Mar;97(3):251-8. https://doi.org/10.1177/0022034517738925 